\title{
Stability of Trisodium Citrate and Gentamicin Solution for Catheter Locks after Storage in Plastic Syringes at Room Temperature
}

\author{
Dennis Cote, Charmaine E Lok, Marisa Battistella, and Lavern Vercaigne
}

\begin{abstract}
Background: Catheter-related infections are a major problem for hemodialysis patients with central venous catheters for vascular access. Catheter lock solutions containing an anticoagulant are used to maintain the patency of the catheter between hemodialysis sessions. There is evidence that the use of lock solutions containing an antibiotic is associated with lower rates of infection but also that these solutions can kill microbes in colonized catheters and thus avoid the risks and costs associated with replacing the catheter.
\end{abstract}

Objective: This stability study was conducted to determine whether an extemporaneously prepared gentamicin-citrate catheter lock solution would retain its potency over time, thus allowing for advance preparation of the solution.

Methods: Catheter lock solutions containing gentamicin alone, citrate alone, and the combination of gentamicin and citrate were prepared aseptically and packaged in polyethylene syringes. The syringes were stored at room temperature. At timed intervals over 112 days, samples were withdrawn for analysis by means of validated high-performance liquid chromatography.

Results: None of the 3 lock solutions showed any evidence of degradation during the 112-day observation period. In the formulation containing both gentamicin $2.5 \mathrm{mg} / \mathrm{mL}$ and sodium citrate $40 \mathrm{mg} / \mathrm{mL}$ $(4 \%)$, there was no change in the concentration of either gentamicin $(p=0.34)$ or citrate $(p=0.55)$. Linear regression analysis of the concentration-time data for the combined formulation showed that $99.97 \%$ of the labelled amount of gentamicin and $101.30 \%$ of the labelled amount of citrate remained at day 112 . The lower limit of the $95 \%$ confidence intervals indicated that more than $98.17 \%$ of the gentamicin and more than $99.57 \%$ of the citrate remained on day 112 .

Conclusion: The results of this study will allow pharmacies to extemporaneously compound the combined gentamicin-citrate catheter lock solution in advance of use. The method described here will yield a stable product for use in clinical applications.

Key words: gentamicin, citrate, stability, catheter lock solution, hemodialysis, high-performance liquid chromatography

Can J Hosp Pharm 2010;63(4):304-311

\section{RÉSUMÉ}

Contexte : Les infections liées aux cathéters sont un problème important chez les patients hémodialysés dont l'abord vasculaire est réalisé à l'aide de cathéters veineux centraux. On a recours à des solutions pour verrou de cathéter contenant un anticoagulant afin de maintenir la perméabilité du cathéter entre les séances d'hémodialyse. Des données montrent que des solutions pour verrou renfermant un antibiotique sont associées à des taux d'infections inférieurs et que ces solutions peuvent tuer les microbes colonisant les cathéters, ce qui permet donc d'éviter les risques et les coûts associés au remplacement des cathéters.

Objectif : Cette étude de stabilité a été menée pour déterminer si une solution extemporanée de gentamicine et de citrate pour verrou de cathéter pouvait conserver sa puissance dans le temps, ce qui permettrait ainsi de préparer la solution à l'avance.

Méthodes : Des solutions pour verrou de cathéter contenant de la gentamicine seule, du citrate seul et l'association gentamicine-citrate ont été préparées selon une méthode aseptique, puis conditionnées dans des seringues de polyéthylène. Les seringues ont été conservées à la température ambiante. À différents points dans le temps sur une période de 112 jours, des échantillons ont été prélevés à des fins d'analyse à l'aide d'une épreuve validée par chromatographie liquide haute performance.

Résultats : Aucune des trois solutions pour verrou n'a montré de signes de dégradation durant les 112 jours de la période d'observation. La préparation contenant la gentamicine à $2,5 \mathrm{mg} / \mathrm{mL}$ et le citrate de sodium à $40 \mathrm{mg} / \mathrm{mL}(4 \%)$ n'a montré aucun changement dans la concentration de gentamicine $(p=0,34)$ et de citrate $(p=0,55)$. Une analyse de régression linéaire des concentrations en fonction du temps de la préparation associant la gentamicine et le citrate a révélé que cette préparation avait retenu 99,97\% de sa concentration initiale de gentamicine et $101,30 \%$ de sa concentration initiale de citrate au jour 112. La limite inférieure de l'intervalle de confiance à $95 \%$ a également révélé que la préparation avait retenu plus de $98,17 \%$ de la gentamicine et plus de $99,57 \%$ du citrate au jour 112 .

Conclusion : Les résultats de cette étude permettront aux pharmacies de préparer à l'avance la solution extemporanée pour verrou de cathéter renfermant l'association gentamicine-citrate. La méthode décrite ici donnera un produit stable pour une utilisation dans des applications cliniques.

Mots clés : gentamicine, citrate, stabilité, solution pour verrou de cathéter, hémodialyse, chromatographie liquide haute performance

[Traduction par l'éditeur] 


\section{INTRODUCTION}

Patheter-related infections are a major problem for hemodialysis patients with central venous catheters for vascular access. Bacteremia may result from microorganisms entering the bloodstream at the catheter insertion site or from contamination of the catheter lumen. ${ }^{1}$ Various strategies may be used to prevent this complication, including aseptic precautions when manipulating or accessing the catheter and scrupulous hygiene of the skin around the catheter exit site. ${ }^{2}$

The formation of a bacterial biofilm on the wall of the catheter lumen has been implicated in catheter colonization. ${ }^{3}$ In most cases of catheter-related bacteremia, treatment with systemic antibiotics alone is insufficient to resolve the infection, because the biofilm provides a nidus for infection and recurrent bacteremia. The affected catheter must usually be removed, but in selected cases a lock solution containing both an antibiotic and an anticoagulant is instilled into the catheter lumen. This approach results in a cure in about two-thirds of cases of catheter-related bacteremia, thus avoiding the risks and costs associated with replacing the catheter. ${ }^{2}$ Lock solutions are used to maintain the patency of the catheter between hemodialysis sessions, and several recent publications have supported the use of antibiotic-anticoagulant lock solutions to reduce the rate of catheter-related infection. ${ }^{4-8}$

Heparin is an anticoagulant that is commonly used for maintaining catheter patency, but citrate has also been shown to be effective in this respect; furthermore, at concentrations of about 30\%, citrate has shown some antimicrobial activity. Although locking solutions containing a high concentration of citrate are effective, they are not used in North America, because of concerns about patient safety, particularly the possibility of cardiac arrest. ${ }^{10}$ Investigations of lower-concentration citrate lock solutions demonstrated that a solution containing $4 \%$ trisodium citrate $(40 \mathrm{mg} / \mathrm{mL})$ was both effective and safe. ${ }^{11,12}$

A number of antibiotics, including vancomycin and gentamicin, have been used in lock solutions. ${ }^{13}$ At present, gentamicin appears to be acceptable for this purpose, and it has been used in combination with citrate as a lock solution. With gentamicin-containing solutions, catheter-related infection rates decreased from about 4 episodes per 1000 catheter days to 0.3 episodes per 1000 catheter days. ${ }^{14,15}$

A mixture of gentamicin and citrate suitable for use as a locking solution is not available commercially, so it must be compounded from commercially available components. Efficiencies in terms of time and cost can be achieved by preparing and storing such solutions in advance of their use, but information regarding the product's stability is required. ${ }^{16,17}$ In one stability study, in which commercial $46.7 \%$ trisodium citrate solution was used to extemporaneously prepare a $4 \%$ solution, there was no change in concentration after 28 days of storage in plastic syringes at room temperature. ${ }^{18}$ Although the compatibility of a gentamicin-citrate solution has been studied, ${ }^{19}$ the findings were of limited value since the investigators only examined the solutions for visual changes over time; they did not measure the concentrations of the components.

This type of admixture prepared in quantity would be considered to have a medium risk of microbial contamination. USP Chapter $<797>$ would assign an expiration period of $30 \mathrm{~h}$ at room temperature and 7 days with refrigeration. ${ }^{16}$ However, expiration periods can be expanded if published data showing compatibility and stability of the product are available and sterility testing is performed. ${ }^{17}$ Therefore, the purpose of this stability study was to determine whether an extemporaneous preparation of a gentamicin-citrate catheter lock solution packaged in prefilled syringes retained its potency over a reasonable period of time, to allow for advance preparation and storage of the solution.

\section{METHODS}

\section{Chemicals, Reagents, and Materials}

The study was performed between November 2007 and May 2008. Commercially prepared gentamicin $40 \mathrm{mg} / \mathrm{mL}$ for injection (Sandoz Canada Inc, Boucherville, Quebec; lot 139819, expiry May 2009), sodium citrate $46.7 \%$ for injection (TriCitrasol, Cytasol Laboratories Inc, Braintree, Massachusetts; lot B82T, expiry January 2011), and USP-grade sterile water for injection (Hospira Health Care Corp, Montréal, Quebec; lot 74-337-DK, expiry January 2011) were used to prepare the study solutions, which were stored in polyethylene syringes with luer-lock caps (MedXL Inc, Montréal, Quebec; lot F86331). Gentamicin sulphate USP (PCCA Canada, London, Ontario; lot C104339) and sodium citrate USP (Spectrum, Gardenia, California; lot KC066) were used as reference standards. High-performance liquid chromatography (HPLC)-grade acetonitrile (lot 891499) and phosphoric acid (lot 082037) and analytical-grade hydrochloric acid (lot 4100030) and sodium hydroxide (lot 016045) were purchased from Fisher Scientific (Nepean, Ontario). Hydrogen peroxide USP (6\%) was purchased from Pure Standard Products (Edmonton, Alberta; lot 189). Phenylisocyanate (Fluka; lot 1378398), triethylamine (lot $047 \mathrm{~K} 1041$ ), and trifluoroacetic acid (Fluka; lot 046710) were purchased from Sigma-Aldrich (St Louis, Missouri). Samples for analysis were stored frozen in cryovials (Nunc, Rochester, New York; lot 089675), and the mobile phase was filtered through Supor-200 polyethersulfone $0.2-\mu \mathrm{m}$ membranes (Pall, Gelman Laboratories, East Hills, New York; lot 51321). 


\section{HPLC Assays}

The chromatographic system was manufactured by Knauer (Berlin, Germany) and consisted of a Wellchrom K-501 pump, a Wellchrom K-2501 variable-wavelength ultraviolet (UV) detector, a Basic-Marathon autosampler, and a Wellchrom HPLC interface box. Eurochrome 2000 operating and data-acquisition software (Knauer, Berlin, Germany) was used. All chromatography was performed at room temperature, and the temperature of the experimental environment was recorded periodically over the study period.

For the gentamicin analysis, an isocratic reversed-phase HPLC method based on that of Kim and others ${ }^{20}$ was followed, except for use of a $150 \times 4.6 \mathrm{~mm}$ cyano column with a particle size of $4 \mu \mathrm{m}$ (Jones, Hengoed, UK; lot 9650001) instead of a C18 column. The mobile phase consisted of acetonitrilewater-trifluoroacetic acid $(400: 600: 1 \mathrm{v} / \mathrm{v} / \mathrm{v})$ at a flow rate of $1.0 \mathrm{~mL} / \mathrm{min}$. The injection volume was $20 \mu \mathrm{L}$, detection was by UV absorbance at $240 \mathrm{~nm}$, and the concentration of gentamicin was quantified by means of external standards and peak areas. A stock solution containing gentamicin $400 \mu \mathrm{g} / \mathrm{mL}$ in water was made fresh daily and was used to prepare the standard solutions, also in water. Because gentamicin has no inherent UV-absorbing properties, phenylisocyanate derivatives of the drug, which absorb strongly at $240 \mathrm{~nm}$, were prepared according to the method described by Kim and others. ${ }^{20,21}$ Briefly, each sample was diluted with water to a gentamicin concentration of about $250 \mu \mathrm{g} / \mathrm{mL}$. A $0.5-\mathrm{mL}$ volume of this solution was then mixed with $0.25 \mathrm{~mL}$ of a $0.5 \% \mathrm{v} / \mathrm{v}$ solution of triethylamine in acetonitrile, and $0.25 \mathrm{~mL}$ of a $0.5 \% \mathrm{v} / \mathrm{v}$ solution of phenylisocyanate in acetonitrile was added. Kim and other ${ }^{20}$ reported that the reaction is very rapid at room temperature and the derivatives are stable for at least $24 \mathrm{~h}$ at room temperature. The phenylisocyanate and triethylamine reagents are also stable at room temperature for at least $24 \mathrm{~h}^{21}$

For citrate analysis, an isocratic ion-exchange HPLC method, as described in a Supelco application note, ${ }^{22}$ was used. The mobile phase consisted of $0.1 \% \mathrm{w} / \mathrm{v}$ phosphoric acid at a flow rate of $0.5 \mathrm{~mL} / \mathrm{min}$. A $300 \times 7.8 \mathrm{~mm}$ polystyrene divinylbenzene resin column (Supelcogel C-610H, Supelco Canada, Mississauga, Ontario; lot 59320U) was used. The injection volume was $20 \mu \mathrm{L}$, detection was by UV absorbance at $210 \mathrm{~nm}$, and the concentration of citrate was quantified with external standards. A stock solution containing sodium citrate $3200 \mu \mathrm{g} / \mathrm{mL}$ in water was made fresh daily and was used to prepare the standard solutions. Samples were prepared by diluting the test solution with water to a concentration of sodium citrate of about $1600 \mu \mathrm{g} / \mathrm{mL}$.

A typical run for analysis of the stored samples was 14 samples, 1 blank, and 6 standards. For gentamicin, the standards consisted of 2 each at 160, 240, and $320 \mu \mathrm{g} / \mathrm{mL}$, representing about $65 \%, 100 \%$, and $130 \%$ of the target concentration; for citrate the standards consisted of 2 each at 800,1600 , and $2400 \mu \mathrm{g} / \mathrm{mL}$, representing about $50 \%, 100 \%$, and $150 \%$ of the target concentration. The samples were diluted in water to $250 \mu \mathrm{g} / \mathrm{mL}$ for gentamicin $(1: 10)$ and to $1600 \mu \mathrm{g} / \mathrm{mL}$ for citrate (1:25). The resulting 21 vials were coded and randomized, phenylisocyanate derivatives were prepared in the case of the gentamicin samples, and the samples were run. Quantitation was achieved by regression analysis of the standards, with the slope and intercept coefficients being used to calculate the concentrations of the samples from their respective peak areas.

\section{Validation of Gentamicin Assay}

Three solutions of gentamicin standard ( $40 \mathrm{mg}$ dissolved and made up to $100 \mathrm{~mL}$ in water) were prepared. These solutions were further diluted with water to prepare 3 sets of gentamicin solutions with concentrations of 80, 160, 240,320, and $400 \mu \mathrm{g} / \mathrm{mL}$. Phenylisocyanate derivatives were prepared from samples of each of these solutions, and the resulting solutions were analyzed as described above. These data were used to calculate the linearity and range of the method, with linear regression of response or peak area as a function of concentration.

For gentamicin, $240 \mu \mathrm{g} / \mathrm{mL}$ was selected as the target concentration, and the solutions at 160,240 , and $320 \mu \mathrm{g} / \mathrm{mL}$, representing about $66 \%, 100 \%$, and $130 \%$ of the target concentration, were used to determine accuracy and precision. The coefficients from the previous regression analysis were used to calculate a concentration value for each standard solution, which were expressed as a percentage (calculated concentration divided by theoretical concentration). Accuracy was assessed from the mean of the 9 values and precision from the relative standard deviation (SD) of this mean. On the following day, 3 fresh solutions were prepared and diluted to generate another 3 solutions with concentrations of 160,240 , and $320 \mu \mathrm{g} / \mathrm{mL}$. Phenylisocyanate derivatives were prepared and analyzed. The resulting data and the data from the previous day were used to calculate between-day precision.

Forced degradation was used to demonstrate the specificity of the method. One-millilitre volumes of each of $6 \% \mathrm{H}_{2} \mathrm{O}_{2}$, $0.1 \mathrm{mmol} / \mathrm{L} \mathrm{HCl}$, and $0.1 \mathrm{mmol} / \mathrm{L} \mathrm{NaOH}$ were mixed individually with $1.0 \mathrm{~mL}$ of gentamicin $40 \mathrm{mg} / \mathrm{mL}$ in $100-\mathrm{mL}$ flasks and left overnight. A control flask, containing only the gentamicin solution, was also prepared. The next morning, each flask was made up to volume with water, and four $0.5-\mathrm{mL}$ samples were taken from each flask for preparation of phenylisocyanate derivatives and HPLC analysis.

To determine whether the presence of citrate would interfere with analysis of gentamicin, samples containing gentamicin $2.5 \mathrm{mg} / \mathrm{mL}$ and sodium citrate $40 \mathrm{mg} / \mathrm{mL}$ were also prepared. For this part of the study, 4 solutions were prepared: 
gentamicin alone, citrate alone, gentamicin and citrate combined, and a control (distilled water). Phenylisocyanate derivatives were prepared from 4 samples from each flask, and these solutions were analyzed for gentamicin content.

\section{Validation of Citrate Assay}

Three solutions of sodium citrate standard $(320 \mathrm{mg}$ dissolved and made up to $100 \mathrm{~mL}$ in water) were prepared. These solutions were further diluted with water to prepare 3 sets of citrate solutions with concentrations of $400,800,1600$, 2400 , and $3200 \mu \mathrm{g} / \mathrm{mL}$. Samples from each of these solutions were analyzed using the HPLC assay described above. These data were used to calculate the linearity and range of the method, with linear regression of response or peak area as a function of concentration.

For sodium citrate, $1600 \mu \mathrm{g} / \mathrm{mL}$ was selected as the target concentration, and the solutions at 800, 1600, and $2400 \mu \mathrm{g} / \mathrm{mL}$, representing about $50 \%, 100 \%$, and $150 \%$ of the target concentration, were used to determine accuracy and precision. The coefficients from the previous regression analysis were used to calculate a concentration value for each standard solution, which were expressed as a percentage (calculated concentration divided by theoretical concentration). Accuracy was assessed from the mean of the 9 values and precision from the relative SD of this mean. On the following day, 3 fresh solutions were prepared and diluted to generate another 3 solutions with concentrations of 800,1600 , and $2400 \mu \mathrm{g} / \mathrm{mL}$. Samples of these solutions were analyzed. The resulting data and the data from the previous day were used to calculate between-day precision.

Forced degradation was used to demonstrate the specificity of the method. One-millilitre volumes of each of $6 \% \mathrm{H}_{2} \mathrm{O}_{2}$, $1 \mathrm{mmol} / \mathrm{L} \mathrm{HCl}$, and $1 \mathrm{mmol} / \mathrm{L} \mathrm{NaOH}$ were mixed individually with $0.342 \mathrm{~mL}$ of sodium citrate $46.7 \%$ in 100 -mL flasks and left overnight. Two controls, one consisting of $0.342 \mathrm{~mL}$ of citrate and one containing only $1.0 \mathrm{~mL}$ of $\mathrm{H}_{2} \mathrm{O}_{2}$, were also prepared. The next morning, each flask was made up to volume with water, and four $0.1-\mathrm{mL}$ samples were taken from each flask for HPLC analysis.

To determine whether the presence of gentamicin would interfere with analysis of citrate, samples containing sodium citrate $40 \mathrm{mg} / \mathrm{mL}$ and gentamicin $2.5 \mathrm{mg} / \mathrm{mL}$ were also prepared. For this part of the study, 4 samples were prepared; citrate alone, gentamicin alone, citrate and gentmicin combined, and a control (distilled water). Four samples from each flask were analyzed for citrate content.

\section{Protocol for Stability Study}

Three formulations were evaluated for compatibility and stability. These were prepared, using aseptic technique, from the commercially available gentamicin $(40 \mathrm{mg} / \mathrm{mL})$ and trisodium citrate $(46.7 \%$ for injection, diluted with water). Formulation A consisted of gentamicin $2.5 \mathrm{mg} / \mathrm{mL}$, formulation B consisted of sodium citrate $40 \mathrm{mg} / \mathrm{mL}$, and formulation $\mathrm{C}$ consisted of both gentamicin and sodium citrate at concentrations of 2.5 and $40 \mathrm{mg} / \mathrm{mL}$, respectively. A $30-\mathrm{mL}$ volume of each formulation was prepared, and 5-mL aliquots of each formulation were packaged into six $5-\mathrm{mL}$ polyethylene syringes. The syringes were closed with luer-lock syringe tips and were stored at room temperature in a plastic bin with an opaque, snug-fitting lid.

On days $0,7,14,28,42,56$, and 112 , a sample of about $0.8 \mathrm{~mL}$ was withdrawn from each of 4 randomly selected syringes for each formulation. These samples were placed in 1.8-mL screw-top cryovials and stored at $-20^{\circ} \mathrm{C}$ until analysis. Both gentamicin and citrate have been shown to be stable for 6 months when frozen and stored at $-20^{\circ} \mathrm{C} .{ }^{23,24}$ For gentamicin analysis, the samples were diluted 1:1 with water to give a nominal concentration of $250 \mathrm{~g} / \mathrm{mL}$; phenylisocyanate derivatives were prepared from $0.5-\mathrm{mL}$ volumes of these solutions, as previously described, and analyzed by means of HPLC. For citrate analysis, samples were diluted 1:25 with water to generate a nominal concentration of $1600 \mu \mathrm{g} / \mathrm{mL}$, and these solutions were analyzed by HPLC. The concentration of gentamicin and citrate was quantified with reference to standards analyzed concurrently with the samples. At the time of analysis, all samples, standards, and a blank were coded and analyzed in random order.

At the start and finish of the study, the $\mathrm{pH}$ of the formulations was assessed using a $\mathrm{pH}$ meter (Accumet Basic AB15, Fisher Scientific, Nepean, Ontario). Colour and clarity were assessed visually.

\section{Statistical Analysis}

Statistical analyses were performed with SigmaStat (SPSS Inc, Chicago, Illinois) and Excel 2000 (Microsoft) software. All statistical analyses were performed at the $95 \%$ significance level, and data are presented as means $\pm \mathrm{SD}$, unless indicated otherwise. Linear regression models were constructed to estimate the amount, with 95\% confidence intervals (CIs), of gentamicin and citrate remaining at the end of the 112-day observation period. In each model, the independent variable was time, and the dependent variables were the concentrations of gentamicin and citrate. Analysis of variance (ANOVA) was used to test changes in concentration over time.

\section{RESULTS}

\section{Validation of Gentamicin Assay}

Regression analysis of peak area as a function of concentration for standard solutions of gentamicin with concentra- 
tions ranging from 80 to $400 \mu \mathrm{g} / \mathrm{mL}$ demonstrated linearity, and the coefficient of determination $\left(r^{2}\right)$ was $0.9924(n=15)$. The 3 sets of solutions at concentrations of 160, 240, and $320 \mu \mathrm{g} / \mathrm{mL}$ had an accuracy of $101.0 \%(n=9)$ and a withinday precision, expressed as relative $\mathrm{SD}$, of $2.21 \%(n=9)$. The between-day precision was $2.52 \%(n=18)$. Chromatograms of the phenylisocyanate derivatives prepared from the gentamicin standard showed 3 peaks eluting at 5.3, 5.6, and $6.0 \mathrm{~min}$, which represented gentamicin $\mathrm{C}_{1}, \mathrm{C}_{1 \mathrm{~A}}$, and $\mathrm{C}_{2}{ }^{20}$ To quantify the gentamicin, the areas of these 3 peaks were summed. Gentamicin $\mathrm{C}_{2}$ and $\mathrm{C}_{2 \mathrm{~A}}$ are isomers that this assay was unable to resolve; they co-eluted as one peak, so the chromatograms showed 3 rather than 4 peaks. Other authors have quantified gentamicin on the basis of the sum of 3 peaks. ${ }^{25,26}$

The specificity of the method was established using forced degradation. The samples mixed with $0.1 \mathrm{mmol} / \mathrm{L} \mathrm{HCl}$ showed no indication of degradation, and the gentamicin concentration remained essentially unchanged, with $99.63 \% \pm 0.29 \%$ remaining for the $\mathrm{HCl}$-treated samples and $99.10 \% \pm 0.57 \%$ remaining for the control. The samples treated with $0.1 \mathrm{mmol} / \mathrm{L} \mathrm{NaOH}$ showed some degradation, with $98.21 \% \pm$ $0.29 \%$ remaining and the presence of a new peak at $4.4 \mathrm{~min}$. The samples mixed with $\mathrm{H}_{2} \mathrm{O}_{2}$ also showed signs of degradation, with 4 new peaks appearing on the chromatogram. Quantification of the gentamicin in these samples indicated that only $18.11 \% \pm 0.83 \%$ of the drug originally present remained. Three of the new peaks eluted early, with retention times of 2.4, 3.7, and $4.4 \mathrm{~min}$, respectively, and the fourth eluted late, at about $8.4 \mathrm{~min}$. The peaks associated with gentamicin eluted between 5 and 6 min. Chromatograms of the control and peroxide-treated samples are presented in Figure 1.

Samples containing gentamicin alone, citrate alone, gentamicin and citrate combined, and a control (distilled water) were analyzed to determine whether the presence of citrate in samples would interfere with analysis of gentamicin. The 2 solutions containing gentamicin yielded similar chromatograms, with no statistically significant differences between them in terms of peak area $(p=0.92)$. The sample containing only citrate generated no peaks and was identical with the chromatogram of the control preparation. These results indicated that the presence of citrate in the sample did not affect the analysis of gentamicin.

\section{Validation of Citrate Assay}

Regression analysis of peak area as a function of concentration for standard solutions of sodium citrate with concentrations ranging from 400 to $3200 \mu \mathrm{g} / \mathrm{mL}$ demonstrated linearity, and the coefficient of determination $\left(r^{2}\right)$ was $0.9996(n=15)$. The 3 sets of solutions at concentrations 800, 1600, and $2400 \mu \mathrm{g} / \mathrm{mL}$ had an accuracy of $99.61 \%(n=9)$ and a withinday precision, expressed as relative $\mathrm{SD}$, of $1.06 \%(n=9)$. The

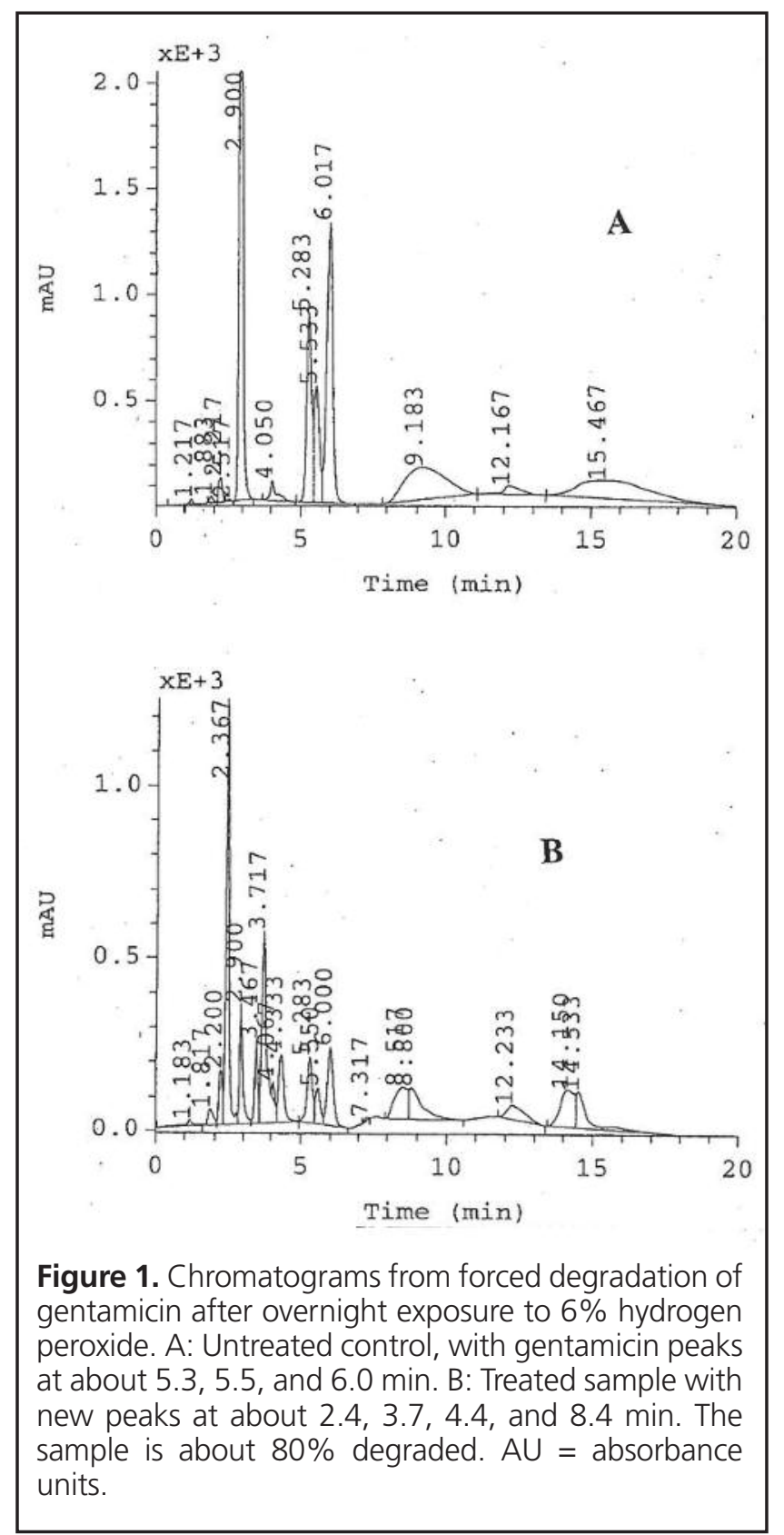

between-day precision was $0.88 \%(n=18)$. Chromatograms of citrate showed one peak eluting at $11.0 \mathrm{~min}$.

Forced degradation was used to demonstrate the specificity of the method. The samples mixed with either $1 \mathrm{mmol} / \mathrm{L} \mathrm{HCl}$ or $1 \mathrm{mmol} / \mathrm{L} \mathrm{NaOH}$ showed no indication of degradation, and the citrate concentration remained essentially unchanged, with $99.92 \% \pm 0.08 \%$ remaining for the $\mathrm{HCl}$-treated samples, $99.97 \% \pm 0.14 \%$ remaining for the $\mathrm{NaOH}$-treated samples, and $100.0 \% \pm 0.39 \%$ remaining for the control. The sample mixed with $\mathrm{H}_{2} \mathrm{O}_{2}$ did show signs of degradation. The content remaining dropped to $91.98 \% \pm 0.21 \%$ and a new peak appeared at $14.5 \mathrm{~min}$, but it was too small to be integrated. The 

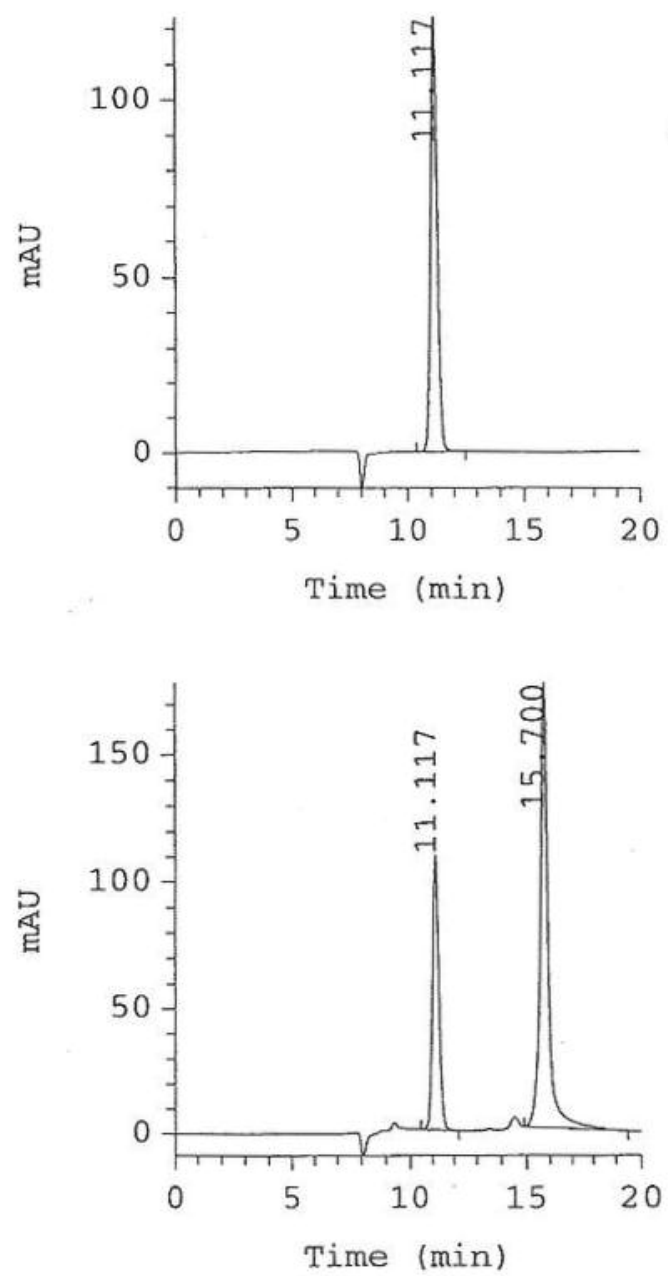

Figure 2. Chromatograms from forced degradation of citrate after overnight exposure to $6 \%$ hydrogen peroxide. A: Untreated control with citrate peak at about $11.1 \mathrm{~min}$. B: Treated sample with new peak at about $14.5 \mathrm{~min}$. The hydrogen peroxide eluted at about $15.7 \mathrm{~min}$. The sample is about $10 \%$ degraded. $\mathrm{AU}=$ absorbance units.

peak for citrate had a retention time of $11.1 \mathrm{~min}$, and the peak for $\mathrm{H}_{2} \mathrm{O}_{2}$ had a retention time of $15.7 \mathrm{~min}$. Chromatograms of the control and peroxide-treated samples are presented in Figure 2.

Samples containing citrate alone, gentamicin alone, both citrate and gentamicin, and a control (distilled water) were analyzed to determine whether the presence of gentamicin in samples would interfere with analysis of citrate. The 2 solutions containing citrate yielded similar chromatograms, with no statistically significant difference between them in terms of peak area $(p=0.44)$. The sample containing only gentamicin generated no peaks under the conditions of the assay. These results indicated that the presence of gentamicin in the sample did not affect the analysis of citrate.

\section{Stability Study}

Four samples of each formulation were withdrawn at intervals over 112 days, stored frozen at $-20^{\circ} \mathrm{C}$, and then analyzed for concentration of gentamicin and citrate using the validated HPLC methods described above. Analysis of all samples was complete by study day 126 , so the longest storage time in the freezer was 126 days (for the samples obtained on day 0); the median storage time for the frozen samples was 98 days. All of the solutions retained at least $99 \%$ of the labelled concentration over time (Table 1). None of the chromatograms for either gentamicin or citrate showed the presence of unexpected peaks or peaks associated with the breakdown products seen in the forced degradation studies.

For each formulation, the concentration of drug present in the 4 samples obtained at each time point were compared by ANOVA. For formulation A (gentamicin $2.5 \mathrm{mg} / \mathrm{mL}$ ), there was no significant change in gentamicin concentration over the 112-day study period $(p=0.60)$. Similarly, for formulation B (sodium citrate $40 \mathrm{mg} / \mathrm{mL}$ ), there was no significant change in citrate concentration over the same period $(p=0.57)$. For formulation $\mathrm{C}$ (gentamicin and citrate combined), there was no change in the concentration of either gentamicin $(p=0.34)$ or citrate $(p=0.055)$ over the study period.

None of the formulations showed a significant change in either gentamicin or citrate concentration over the 112-day period (Table 1). This result was confirmed with regression analysis of concentration as a function of time: in all cases, the slope of the regression line was not significantly different from zero $(p>0.05)$. From the linear regression analysis of the concentration-time data of formulation $\mathrm{C}$, we calculated that $99.97 \%$ of the labelled amount of gentamicin and $101.3 \%$ of the labelled amount of citrate remained at day 112. The lower limit of the $95 \%$ CI also indicated that more than $98.17 \%$ of the gentamicin and more than $99.57 \%$ of the citrate remained on day 112 .

The $\mathrm{pH}$ of each formulation did not change significantly from baseline to the end of the observation period $(p>0.05$ for all comparisons). The initial and final $\mathrm{pH}$ values were $4.86 \pm 0.06$ and $4.97 \pm 0.10$, respectively, for formulation $\mathrm{A}$; $6.56 \pm 0.05$ and $6.60 \pm 0.02$, respectively, for formulation B; and $6.47 \pm 0.03$ and $6.50 \pm 0.02$, respectively, for formulation C. At the end of the study period, samples of each formulation remained clear and colourless by visual inspection. The storage temperature was $23.9 \pm 0.9^{\circ} \mathrm{C}(n=10)$ over the course of the study.

\section{DISCUSSION}

The HPLC methods used for analysis of gentamicin and citrate proved acceptable, and for both methods the validation studies indicated suitable linearity over an acceptable range, as 
Table 1. Concentrations of Gentamicin and Citrate for the 3 Study Formulations as a Function of Time, Expressed as Percentage of Label Content*

\begin{tabular}{lccrc} 
& & & \multicolumn{2}{c}{ Formulation C } \\
\cline { 4 - 5 } Study Day & Formulation A & Formulation B & & \multicolumn{1}{c}{ (Gentamicin) } \\
(Citrate) & $103.3 \pm 0.64$ & $102.0 \pm 0.75$ & $102.8 \pm 2.15$ \\
\hline 0 & $101.3 \pm 2.27$ & $104.3 \pm 0.29$ & $99.9 \pm 1.64$ & $101.5 \pm 1.55$ \\
7 & $102.8 \pm 0.87$ & $104.6 \pm 2.61$ & $100.6 \pm 0.13$ & $102.2 \pm 1.03$ \\
14 & $101.4 \pm 3.19$ & $103.9 \pm 1.54$ & $99.6 \pm 0.60$ & $101.8 \pm 0.56$ \\
28 & $101.1 \pm 1.94$ & $100.9 \pm 1.73$ & $102.6 \pm 1.92$ \\
42 & $100.9 \pm 1.30$ & $104.2 \pm 0.94$ & $100.9 \pm 1.94$ \\
56 & $101.8 \pm 2.30$ & $104.4 \pm 0.84$ & $100.4 \pm 2.08$ & $100.8 \pm 1.54$ \\
112 & $99.9 \pm 1.13$ & $103.4 \pm 0.59$ & $100.1 \pm 1.86$ & $101.6 \pm 0.90$ \\
\hline
\end{tabular}

*Values are means \pm standard deviation $(n=4)$.

well as suitable accuracy and precision. The specificity of the methods was established by means of forced degradation, and the peaks for the degradation products all had retention times well separated from those of the analytes. There were no changes in peak symmetry or retention times for parent compounds over the validation period. The presence of citrate was shown to not interfere with the analysis of gentamicin, and the presence of gentamicin was shown to not interfere with the analysis of citrate.

For none of the formulations (gentamicin alone, citrate alone, gentamicin and citrate combined) were there any significant changes in concentration of either gentamicin or citrate over the 112-day study period.

\section{CONCLUSIONS}

The results of this study indicate that an admixture of gentamicin and citrate at final concentrations of 2.5 and $40 \mathrm{mg} / \mathrm{mL}$ (4\%), respectively, can be mixed and stored in polyethylene syringes and is stable at room temperature for at least 112 days with minimal change to the initial concentrations. In assigning a beyond-use date, however, sterility aspects of the product must also be considered, as outlined by the USP. ${ }^{16}$ This information will allow extemporaneous compounding of this catheter lock solution in advance of use and will provide a stable product for use in clinical applications.

\section{References}

1. Taal MW, Fluck RJ, McIntyre CW. Preventing catheter related infections in hemodialysis patients. Curr Opin Nephrol Hypertens 2006;15(6): 599-602.

2. Allon M. Dialysis catheter-related bacteremia: treatment and prophylaxis. Am J Kidney Dis 2004;44(5):779-791.

3. Passerini L, Lam K, Costerton JW, King EG. Biofilms on indwelling vascular catheters. Crit Care Med 1992;20(5):665-673.

4. Labriola L, Crott R, Jadoul M. Preventing haemodialysis catheter-related bacteremia with an antimicrobial lock solution: a meta-analysis of prospective trials. Nephrol Dial Transplant 2008;23(5):1666-1672.

5. Shanks RM, Sargent JL, Martinez RM, Graber ML, O’Toole GA. Catheter lock solutions influence staphylococcal biofilm formation on abiotic surfaces. Nephrol Dial Transplant 2006;21(8):2247-2255.
6. Katneni R, Hedayati SS. Central venous catheter-related bacteremia in chronic hemodialysis patients: epidemiology and evidence-based management. Nat Clin Prac Nephrol 2007;3(5);256-266.

7. Bleyer AJ. Use of antimicrobial catheter lock solutions to prevent catheterrelated bacteremia. Clin J Am Soc Nephrol 2007;2(5):1073-1078.

8. Yahav D, Rozen-Zvi B, Gafter-Gvili A, Leibovici L, Gafter U, Paul M. Antimicrobial lock solutions for the prevention of infections associated with intravascular catheters in patients undergoing hemodialysis: systematic review and meta-analysis of randomized, controlled trials. Clin Infect Dis 2008;47(1):83-93.

9. Weijmer MC, Debets-Ossenkopp YJ, Van De Vondervoort FJ, ter Wee PM. Superior antimicrobial activity of trisodium citrate over heparin for catheter locking. Nephrol Dial Transplant 2002;17(12):2189-2195.

10. Polaschegg HD, Sodemann K. Risks related to catheter locking solutions containing concentrated citrate. Nephrol Dial Transplant 2003; 18(12):2688-2690.

11. Lok CE, Appleton D, Bhola C, Khoo B, Richardson RM. Trisodium citrate $4 \%$ - an alternative to heparin capping of haemodialysis catheters. Nephrol Dial Transplant 2007;22(2):477-483.

12. Grudzinski L, Quinan P, Kwok S, Pierratos A. Sodium citrate 4\% locking solution for central venous dialysis catheters - an effective, more cost-effective alternative to heparin. Nephrol Dial Transplant 2007;22(2):471-476.

13. Bastani B, Amin K, Herr A. Prolonged stability of stored vancomycin, gentamicin and heparin for use in the antibiotic-lock technique. ASAIOJ 2005;51(6):761-763.

14. Dogra GK, Herson H, Hutchinson B, Irish AB, Heath $\mathrm{CH}$, Golledge C, et al. Prevention of tunneled hemodialysis catheter-related infections using catheter-restricted filling with gentamicin and citrate: a randomized controlled study. J Am Soc Nephrol 2002;13(8):2133-2139.

15. Nori US, Manoharan A, Yee J, Besarab A. Comparison of low-dose gentamicin with minocycline as catheter lock solutions in the prevention of catheter-related bacteremia. Am J Kidney Dis 2006;48(4):596-605.

16. Pharmaceutical compounding—sterile preparations: general chapter <797>. In: United States Pharmacopeia 31 - National Formulary 26. Rockville (MD): United States Pharmacopeial Convention Inc; 2008. p. 329-336.

17. Kastango ES, Bradshaw BD. USP chapter 797: establishing a practice standard for compounding sterile preparations in pharmacy. Am J Health Syst Pharm 2004;61:1928-1938.

18. Levesque N, Girard L, Leger J, Dorval M. Stability of trisodium citrate $4.0 \%$ and $46.7 \%$ in polyvinyl chloride syringes. Can J Hosp Pharm 2001;54(4):264-268.

19. Wazny L, Walker S, Moist L. Visual compatibility of gentamicin sulfate and 4\% sodium citrate solutions. Am J Health Syst Pharm 2005;62(15): 1548-1550.

20. Kim BH, Lee SC, Lee HJ, Ok JH. Reversed-phase liquid chromatographic method for the analysis of aminoglycoside antibiotics using pre-column 
derivatization with phenylisocyanate. Biomed Chromatogr 2003;17(6):396403

21. Kim BH, Kim YK, Ok JH. Development of liquid chromatographic method for the analysis of kanamycin residues in varicella vaccine using phenylisocyanate as a derivatization reagent. J Chromatogr B Biomed Sci Appl 2001;752(1):173-177.

22. Application note 21. Separation of organic acids in beverages using a Supelcogel ${ }^{\mathrm{TM}}$ C-610H HPLC column. ChromFax No. 3940211995. St Louis (MO): Supelco Sigma-Aldrich; 1995.

23. Auge C, Gourdier B, Reither-Chenel V, Rey JB. Development of a readyto-use antibiotic conservation solution for arterio-venous grafts. PDA J Pharm Sci Tech 2005;60(3):182-190.

24. Heger A, Svae TE, Neisser-Svae A, Jordan S, Behizad M, Römisch J. Biochemical quality of the pharmaceutically licensed plasma OctaplasLG after implementation of a novel prion protein [PrPSc] removal technology and reduction of the solvent/detergent [S/D] process time. Vox Sang 2009;97(3):219-225.

25. Isoherranen N, Soback S. Determination of gentamicins C1, C1a, and C2 in plasma and urine by HPLC. Clin Chem 2000;46(6):837-842.

26. Fabre H, Sekkat M, Blanchin MD, Mandrou B. Determination of aminoglycosides in pharmaceutical formulations - II. High-performance liquid chromatography. J Pharm Biomed Anal 1989;7(12):1711-1718.
Dennis Cote, BSc(Pharm), MSc, PhD, is an Instructor with the Faculty of Pharmacy, University of Manitoba, Winnipeg, Manitoba.

Charmaine E Lok, MD, FRCPC, is Associate Professor with the Faculty of Medicine, University of Toronto, and Staff Nephrologist with the University Health Network-Toronto General Hospital, Toronto, Ontario.

Marisa Battistella, PharmD, ACPR, is a Clinical Pharmacist Hemodialysis with the University Health Network-Toronto General Hospital, Toronto, Ontario.

Lavern Vercaigne, PharmD, is Associate Professor with the Faculty of Pharmacy, University of Manitoba, Winnipeg, Manitoba.

\section{Address correspondence to:}

Dennis Cote

Faculty of Pharmacy

University of Manitoba

750 McDermot Avenue

Winnipeg MB R3E OT5

e-mail: Dennis_Cote@umanitoba.ca 